\title{
The Dark Side of Extra Role Behaviors: Investigating the Link between Extra-role and Counterproductive Behaviors in Organizations using Moral Licensing Theory
}

\begin{abstract}
Atefeh Sodeiri*
Summary

Most researches in the organizational citizenship behaviors (OCBs) field illustrate a wide range of positive outcomes for both employees and organizations. Some studies have investigated the other side of the coin, as well as the dark side of OCBs and the tendencies of these kinds of behaviors to increase deviant and counterproductive work behaviors (CWBs). Nowadays, investigations about counterproductive work behaviors (CWBs) and the finding of their causes is crucial for organizations. Sometimes the causes of CWBs are clarified, but sometimes extra-role behaviors such as OCBs, which have a negative relation with CWBs as well as organizational culture, can contribute to the formation of counterproductive work behaviors (CWBs). In this paper, by considering moral licensing theory and effects of abusive climate in organizations, as well as dysfunctional culture dimensions, I discuss how employees who engage in OCB may subsequently participate in counterproductive work behaviors (CWBs).
\end{abstract}

Keywords: organizational citizenship behavior (OCBs), moral licensing theory, counterproductive work behavior, organizational culture

JEL: M12, O15, J24

Organizational citizenship behaviors (OCBs) as positive behaviors in an organization have been one of the most important subjects in organizational behavior over the past 30 years. During this time, most of the papers were concentrated on the light edge of OCB and positive effects and consequences of OCBs for employees and organizations. There were fewer articles focusing on the dark side of OCBs. In this paper, I will investigate the way in which background culture effects on the tendency of OCBs to conduct unethical and counterproductive work behaviors (CWBs) with an emphasis on the moral licensing theory.

In this regard and according to the systematic review of literature, I acted in accordance with the following steps. Following the structured literature review (SLR) process suggested by Tranfield, Denyer, and Smart (2003). According to this process, in the first step, the research objective should be determined. In this case, the purpose of my study is to showcase how background culture effects on the tendency of OCBs to conduct unethical and counterproductive work behaviors (CWBs) with an emphasis on the moral licensing theory.

To this aim I searched all articles containing the following key words: Organizational citizenship Behavior (OCBs), Moral licensing theory, Counterproductive work behavior, Organizational culture in different databases such Scopus, Oxford Handbooks Online, Science Direct, Emerald, Elsevier and so on. Those databases contained relevant publications in the area of management. In particular Oxford Handbooks Online was related to the OCBs completely. As illustrated in Figure 1, I searched for any articles or documents that contained the terms of "Organizational Citizenship Behaviors" in any place, such as titles, abstracts or keywords. In this step the results were 2729 articles. I then restricted these results by English language and areas of business management, as well as accounting, psychology and social science. After this restriction the number of search results

* Ferdowski University of Mashhad, Iran \& Faculty of Management, University of Warsaw, Poland, is: https://orcid. org/0000-0002-6032-722X, e-mail: atefeh.sodeirijavadi@mail.um.ac.ir 
was approximately 2374. Afterwards I searched the combination of "Organizational Citizenship Behaviors" and "Counterproductive Work Behavior", which reduced the results to 113 documents. Because my paper has an emphasis on the moral licensing theory, I first searched only for "moral licensing theory" which resulted in 32 articles. I then searched this term with the previous keywords, which resulted in just 1 article. Said this article is the most important article related to my work, and according to the "Academic Journal Guide 2018" it is ranked Q1.

In the next step, it was necessary to know about the definition of organizational culture and various dimensions of organizational culture, as well as knowing about different models of organizational culture. This was however not enough, and I should have investigated the effects of various dimensions of culture on OCBs (354 document results), as well as the effects of organizational culture on forming counterproductive behaviors in an organization (37 document results) separately. After investigating these articles, I chose only 28 of them which were most related to my subjects.

Figure 1. Summery of the SLR

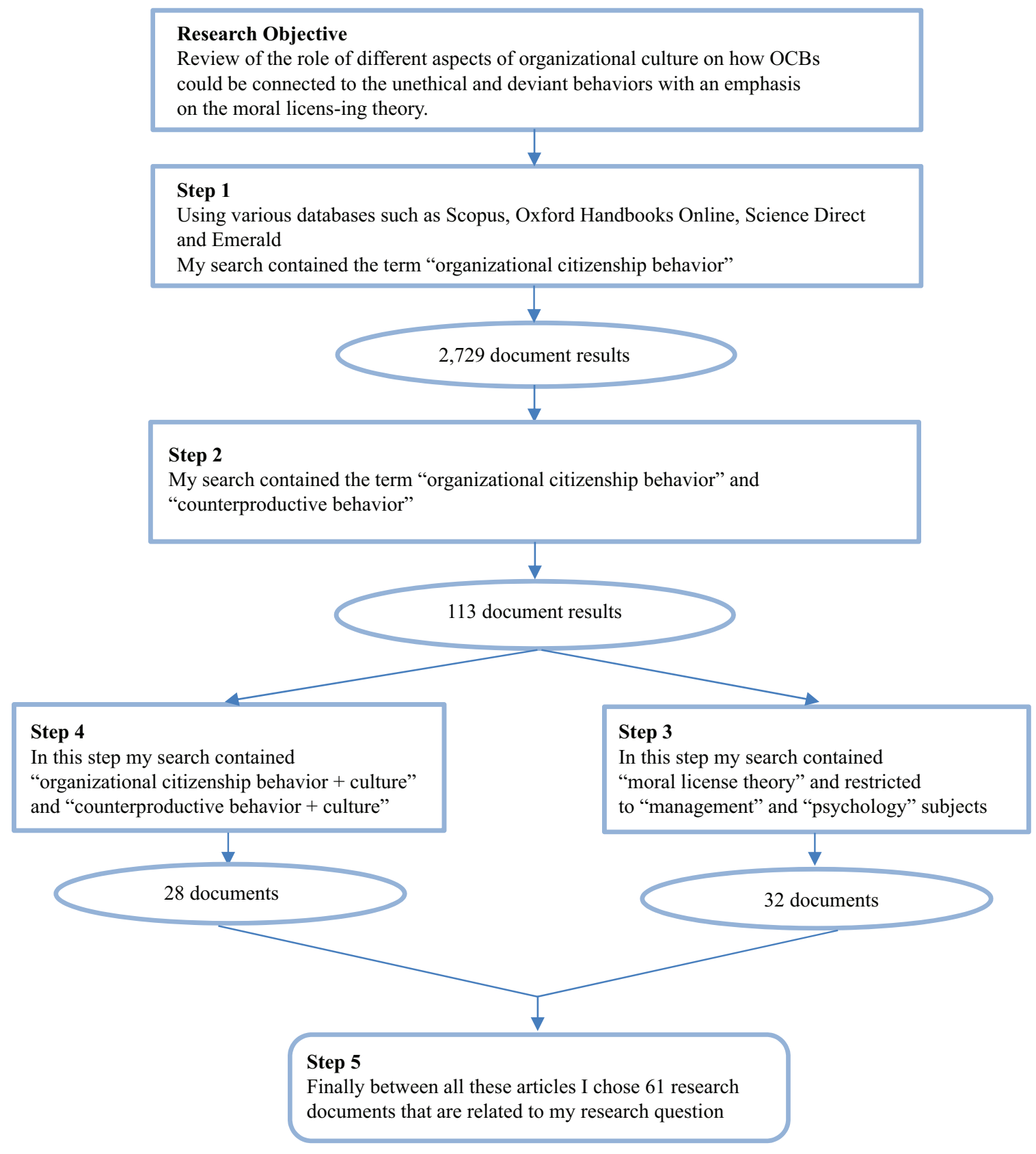




\section{INTRODUCTION}

Employees usually try to contribute positively to the organizational goals. Therefore, employees may go above and beyond of the in-role duties, and they may even engage in extra-role behaviors. Employees can be inclined to engage in such productive behaviors - in-role and extra-role behaviors - because organizations often provide motivations through reward systems or supportive leadership to encourage them toward organizational aims.

Nonetheless, employees may also, at the same time, engage in behaviors that explicitly contradict organizational goals. It is important for organizations and managers to find an explanation for how employees can engage in both - productive and destructive - forms of behaviors. There are various individual and organizational factors to explain this phenomenon. It is clear that productive behaviors not only are effective and efficient for organization, but also lead to improved employee's credit in an organization. In contradiction to the productive behaviors, destructive behaviors not only are detrimental for organizations but also lead to decrease employee's credit in an organization. Since employees do not want to be morally discrediting in their organizations or in view of their colleagues, they try to obtain licenses from various resources such as previous moral behaviors. They do so in order to liberate and allow them to engage in counterproductive work behaviors without worrying about discrediting themselves morally. This study possesses a moral licensing view. It will examine the impact of background culture for explaining how individuals can engage in organizational citizenship behaviors and counterproductive work behavior in an organization at the same time.

Common forms of counterproductive work behavior (CWBs) in organizations consist of ineffective job performance, absenteeism, turnover and unsafe behavior, administrative corruption and so on (Jex \& Britt, 2008).

Counterproductive work behaviors (CWBs) has negative effects on the administrative, economic, social and cultural systems. Therefore, organizational behavior experts are interested in decreasing counterproductive work behaviors because counterproductive work behaviors are disruptive and overpriced in both, a financial fee as well as an emotional fee (Muafi, 2011). To deal with counterproductive work behaviors in the organizations, first, the causes and roots of these behaviors should be identified.

In general, counterproductive work behaviors (CWBs) in the organization are divided in to two general categories: positive counterproductive work behaviors (PCWBs) and negative counterproductive work behaviors (NCWBs) (Appelbaum, Iaconi \& Matousek, 2007).

Depending on the categorizations of counterproductive work behaviors (CWBs) in an organization, typically these behaviors categorize as interpersonal against organizational counterproductive work behavior and mild against severe counterproductive work behavior.

As Figure 2 shows, mild organizational deviant behavior that categorized under the production deviance includes: leaving early, taking excessive beaks, intentionally working slowly and wasting resources. Severe organizational deviant behavior that categorized under the property deviance includes: sabotaging equipment, accepting kickbacks, lying about hours worked and stealing from the company. Mild interpersonal deviant behavior that categorized under the political deviance includes: showing favoritism, gossiping about co-workers, blaming co-workers and competing none beneficially. Severe interpersonal deviant behavior that categorized under the personal aggression includes: sexual harassment, verbal abuse, stealing from co-workers and endangering co-workers (Robinson \& Bennett, 1995).

In contrast, the positive counterproductive work behaviors can be considered as deliberate behaviors that deviate from the standards of a referent group in fair ways. These behaviors are classified under the pro-social behavior such as organizational citizenship behaviors (OCBs), 
whistle-blowing, corporate social responsibility and creativity/innovation (Appelbaum, Iaconi \& Matousek, 2007). All types of pro-social behavior can be classified as positive counterproductive work behavior when they go beyond organizational norms.

Figure 2. Negative deviant workplace behavior

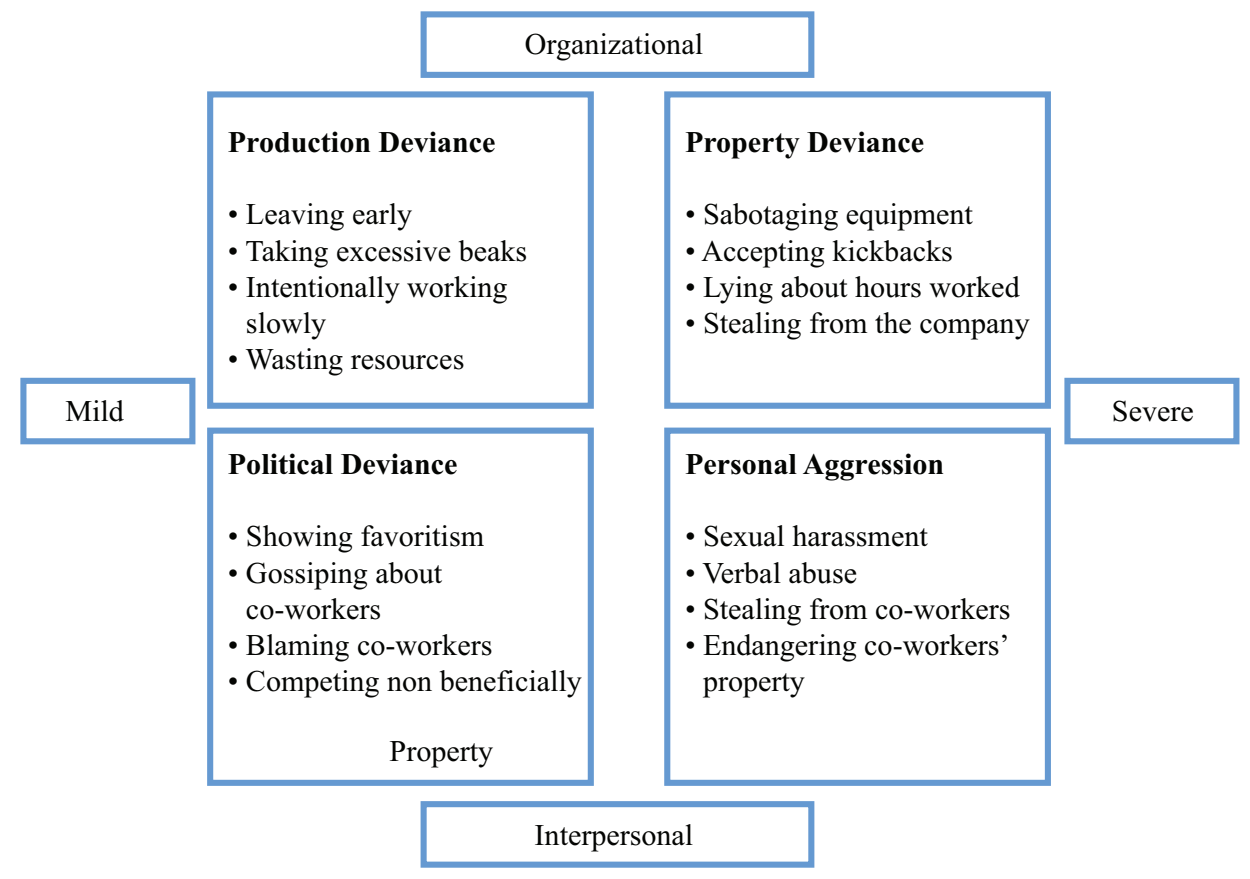

Source: Robinson \& Bennett (1995)

Although most of the researches related to the deviant and counterproductive behavior are often focused on negative deviant workplace behaviors, this research, however, focuses on positive deviant workplace behaviors. This is especially the case for organizational citizenship behavior, as moral behaviors give employees moral licensing in order to engage in counterproductive work behavior.

OCBs are considered behaviors outside of the necessities required of a person at a specific institution, but which will inspire efficiency consecutively of the organization. While OCBs increase the performance of an organization, OCBs behaviors as positive counterproductive work behavior may or may not provide such a goal (Spreitzer \& Sonenshein, 2003). According to the results of empirical studies, employees who usually engage in OCB incline to engage in CWB rarely. Therefore, there is a negative relationship between OCB and CWB. In some cases, positive workplace behaviors such as OCBs provided a moral admirable license for employees to engage in deviant behaviors which are contrary with organizational norms and rules (Klotz \& Bolino, 2013).

In this way, numerous supplementary issues are necessary to be considered. Particularly, (1) there are various types of $\mathrm{OCB}$ and $\mathrm{CWB},(2)$ there are numerous reasons why an employee might engage in $\mathrm{OCB}$ and $\mathrm{CWB}$, and (3) the $\mathrm{OCB}-\mathrm{CWB}$ relationship is probable to be moderated by several variables (Dalal, 2005). According to Dalal (2005), various moderate variables can moderate the relationship between OCBs and CWB. Blanken, van de Ven and Zeelenberg (2015), identified different moderators for the relationship between OCBs and CWBs. One of these moderators of the relationship between OCBs and CWBs is a domain which refers to employees who receive a moral license in a domain. Said employees simultaneously engage in morally questionable behavior in that same domain (specific-domain moral license) or can engage in morally questionable behavior in different domain (cross-domain moral license) (Miller and Effron, 2010). Another moderator 
of the relationship between OCBs and CWBs is related to the real behavior against a proposed behavior. In addition, another moderator which can be considered the most important moderator of the relationship between OCBs and CWBs, is cultural background.

In this study, cultural background is considered as a crucial moderator. This is due to the fact that ethical standards are learned through the process of socialization and therefore are heavily dependent on the cultural environment in which the individual has grown and has been associated with said environment throughout his/her life (Simbrunner \& Schlegelmilch, 2017).

This study will be focused on the influence of cultural background for explaining how individuals can engage in OCBs and CWBs in an organization simultaneously, with consideration of moral licensing theory. In fact, the main question of study is: how do cultural frames influence the transformation of OCBs to deviant behaviors? This study tries to explore how organizational context and cultural background impact an employee's motivations tending from OCBs to CWB while considering the role of moral licensing theory.

\section{LITERATURE REVIEW}

\section{Organizational Citizenship Behavior - Definition}

Nowadays, with growth and complexity of organizations in competitive environments and the importance of behavioral issues in organizations, the attention of organizational behavior researchers is focused on the investigation and identification of causes of both positive and negative organizational work place behaviors. Furthermore, with an increase of unethical and illegal work behaviors in organizations and work places, and according to the researches done (Skyvington, 2014; Klotz \& Bolino, 2013; Yam et al., 2017; Organ, Podsakoff \& MacKenzie, 2005) one of the reasons that has been underestimated in such behaviors are positive counterproductive work behaviors, particularly organizational citizenship behavior (OCBs).

The term "Organizational Citizenship" is identified as an "extra-role" behavior - which is usually not considered by the formal payment system of organizations (Paillé, 2009). They are completely voluntary and vary in the behaviors which are known as intra-role behaviors (Organ, 1988). This was for the first time presented by Organ (1997), who defined Organizational citizenship behaviors (OCBs) as behaviors that are not part of official organizational roles but do affect the organization's performance. In fact OCB is a concept that explains how and why people contribute positively to their organizations beyond their defined work roles (Campbell Pickford \& Joy, 2016).

Usually, OCBs are known as certain behaviors, each of which having certain outcomes for organizations that can affect on the effectiveness of organizations. These behaviors include: altruism which involves helping co-workers; courtesy which is intended to avoiding problems at work, especially with colleagues; conscientiousness which shows that a person is concerned with following rules, being punctual and going beyond minimum organizational necessities; civic virtue which denotes to behaviors that display concern for and commitment to the organization, as well as having constructive involvement in issues of governance and sportsmanship which happens when an employee is willing to tolerate hard circumstances, inconveniences, or other problems at work while keeping their positive outlook with no complains (Halbesleben \& Bellairs, 2018).

\section{Antecedents for Organizational Citizenship Behavior}

Understanding why individuals engage in OCB has become a progressively important issue in this field for behavior researchers and organizations. In general, researches have considered four antecedents for OCBs: 1) individual (or employee) characteristics which can be divided into two items: moral and dispositional items. Moral item relates to the employee satisfaction, organizational commitment, 
perceptions of fairness, as well as perceptions of leader supportiveness. Dispositional item relates to the friendliness and agreeableness, conscientiousness, positive affectivity, and negative affectivity. 2) Task characteristics relates to the task feedback, task reutilization, and inherently satisfying tasks.

3) Organizational characteristics relates to the group cohesiveness, perceived organizational support, and organizational fairness; and leadership behaviors (Farh, Earley \& Lin, 1997).

In other categories, researchers have identified various motives for OCBs that can be related to the conscious and subconscious decision processors which guides behaviors in work environments (Borman \& Penner, 2001; Hanson \& Borman, 2006). These motives can be divided into two categories: positive OCBs motives and negative OCBs motives (dark OCBs motives), and in this regard conditions under which certain motives emerge (Kim et al., 2013; Penner \& Orom, 2010). Individual perceptions of said conditions, such as the situational context and role cognition (Morrison, 1994) are effective.

Engaging in OCBs with positive motives aimed at serving others may be formed by social values. Those who engage in said behaviors are interested in being helpful and shaping positive relationships with others (Rioux \& Penner, 2001). They are also concerned with the welfare of others and the organization (Bolino \& Turnley, 2005; Grant, 2007), and may be motivated by organizational concern - This is showcased by them being interested in doing well and caring about the company, as well as displaying pride in and commitment to the organization (Rioux \& Penner, 2001).

On the other side, most of the researches have indicated that there are certain context inflections and deviation points upon which OCBs go from positive to negative (Grant \& Schwartz, 2011; Pierce \& Aguinis, 2013). In this way, individuals may engage in OCBs aimed at self-serving and personal goals and desires, such as impressing management which is an effort to impact how someone is perceived by others. In the OCBs milieu, impression management is a way in which employees engage in OCBs with the aim of gaining rewards or promotion or other positive outcomes for themselves (Bolino, 1999; Rosenfeld, Giacalone \& Riordan, 1995). In fact, they engage in visible, recognizable practices of citizenship for instrumental purposes. They can also recognize strategic ways to involve OCBs at times in which they would like to augment their reputations (Salamon \& Deutsch, 2006) and avoid looking bad to their colleagues and supervisors (Rioux \& Penner, 2001).

In addition, behaviors can serve one or numerous motives such as the functional approach to behavior and perceived instrumentality to behavior, the motives of which were drawn from social values, organizational concern (positive motives) and also personal and career aims and desires. The functional approach to behavior is related to behaviors in which personal motives are highlight motives, and individuals engage in OCBs for the achievement of their personal aims and desires. Under said approach, they for example engage in OCBs because they can receive praise from the boss or merely for the cause of ingratiation. There is a perceived instrumentality to behaviors related to those possessing career motives are highlight motives, as well as individuals engaging in OCBs for the achievement of their careers and professional aims and desires. Those individuals for instance engage in OCBs for the purpose of obtaining a better position in the future or promotion at work. It's clear that the opportunity for promotion operates as a goal that can be a motivating factor for employees to engage in OCB. For them, OCBs are considered as instrumental to career success (Halbesleben \& Bellairs, 2018).

\section{Consequence of Organizational Citizenship Behaviors}

Organizational citizenship behaviors (OCBs) have been effected positively by organizational performance and outcomes like service quality (Bettencourt \& Brown, 1997; Bell \& Menguc, 2002), organizational commitment (Podsakoff, McKenzie \& Bommer, 1996), job involvement (Dimitriades, 2007), leader-member exchange (Bhal, 2006; Lo, Ramayah \& Kueh Swee Hui, 2006), 
job satisfaction (Chughtai \& Zafar, 2006; Khalid \& Ali, 2005), improved work spirit, confidence, or cohesiveness and sense of belonging among employees (Farh, Earley \& Lin, 1997).

As has been mentioned, OCBs have different dimensions. Each of these dimensions can bring various outcomes for organizations, by for instance helping behaviors lead to predictive outcomes such as product quality, customer satisfaction, performance quality, operating efficiency and revenue (Podsakoff \& MacKenzie, 1994; Walz \& Niehoff, 1996). Civic virtue behaviors facilitate the involvement of employees in governance's issues, therefore they provide constructive suggestions which may save costs (Campbell Pickford \& Joy, 2016). Civic virtue and sportsmanship on the other hand are negatively related to customer complaints (Podsakoff et al., 2000; Walz \& Niehoff, 1996). Other studies showcased altruism and sportsmanship to increase organizational capacity and to appeal to and retain the best employees. Personnel with altruism behavior help each other in the organization, which leads to healthy interpersonal relationships in organizations. Employees in a healthy work environment and positive work climate rarely wish to leave the organization, therefore a reduction of absenteeism can be considered as another result (Podsakoff \& Mackenzie, 1997; Dash \& Pradhan, 2014).

OCBs have been affected negatively by organizational outcomes as well, such as role overload, stress, work-family conflict, and unreciprocated help that lowers productivity (Bergeron et al., 2014; Bolino \& Turnley, 2005; Flynn, 2003). Employees usually face time constraints, therefore when they spend their time engaging in OCBs, they cannot use said time for task performance (Bergeron, 2007). OCBs, which are morally praiseworthy behaviors, in certain circumstances may lead to immoral behaviors in the organization. This is because engaging in OCB may make them feel psychologically free to engage in CWB as an outcome of going the extra mile. This process can be explained by moral licensing theory (Bolino et al., 2013).

\section{OCBs and Counterproductive Behaviors}

Briefly, OCBs are behaviors which support the wider social and psychological environment in which responsibilities are done in organizations and improve organizational functioning (Organ, 1997; Podsakoff, Ahearne \& MacKenzie, 1997). Counterproductive work behaviors (CWBs) are behaviors which intended to hurt the organization or other members of the organization (Spector \& Fox, 2002). Although OCBs and CWBs have a negative relationship, generally, some researches show that OCB could be related to deviant and unethical behaviors in certain circumstances. Bolino \& Klotz (2015) discuss several causes which explain how OCBs exchange to CWBs, including: Resource depletion - OCBs are part of extra-roles and usually go to the extra mile and beyond a formal job. As a result, employees feel overloaded, stressed, fatigued and emotionally exhausted. In this case, OCBs as resource-depleting behaviors, let employees engage in immoral behaviors such as cheating, harming others, wasting time etc. Injustice and anger - Sometimes OCBs may exchange to CWBs because of injustice and underestimated employee activities; Citizenship pressure - As has been mentioned, OCBs are completely voluntary behaviors, but when employees feel an ongoing force to do more than the necessities of their jobs, OCB may miss its quality and intend to CWB.

\section{Moral Licensing Theory}

Moral licensing theory is based on Nisan and Horenczyk's (1990) moral balance theory, according to which "individuals who behave in a morally laudable way, later feel more justified to perform a morally questionable action" (Blanken \& et al, 2014, p. 232). Another definition of moral licensing is a cognitive preconception, which allows individuals to perform immorally without threatening their self-image of being a moral person (Simbrunner \& Schlegelmilch, 2017). Moral licensing theory uses the relationship between OCBs and CWBs as an explanation. According to Nisan and Horenczyk's 
(1990), moral balance theory contains worthless actions by an individual who has recently behaved morally and is valued less rigorously than the same actions conducted by somebody who has recently behaved immorally. In previous researches two unique ways have been considered to form moral licensing: moral credits and moral credentials (Miller \& Effron, 2010). Moral licensing via moral credits is "a dynamic moral self-concept that fluctuates around an equilibrium point", and moral licensing via moral credential is "one's behavioral history makes morally questionable deeds seem as if they were not transgressions at all" (Yam and et al., 2017, p. 9).

The occurrence of moral license is related to a person's self-concept - with concern to morality that self-concept is based on person's cultural background. While moral license can have various causes from racism, sexism, over selfishness to environmental friendliness, we consider cultural background to be one of the most important causes for moral licensing. On the other hand, conditions can be effective in shaping moral license. In addition, whether a person considers herself/himself as a religious person can be affected by forming moral licensing. (Simbrunner \& Schlegelmilch, 2017).

\section{Licensing to Counterproductive Behaviors: Considering the Role of OCBs}

Based on moral balance theory (Nisan \& Horenczyk, 1990) when individuals engage in voluntary counterproductive or deviant behaviors, their self-concept decreases. Therefor they are motivated to increase their self-concept and tend to create balanced moral equilibrium through positive and good behaviors, which is called moral cleanse (Yam \& et al., 2017). In contrast, when individuals engage in morally admirable behaviors such as OCBs, their self-concept increases and subsequently they allow themselves to behave immorally. As a matter of fact, they grant themselves a moral license to engage in negative behaviors (Klotz \& Bolino, 2013). It should be mentioned that the acquisition of moral license does not always lead to the formation of deviant or counterproductive behaviors. In fact, employees with a moral license don't seek deviant behaviors aggressively, but it can be considered as an opportunity to engage in deviant behaviors.

In the workplace, employees engage in broad performance domains such as task performances, organizational citizenship behaviors and counterproductive work behaviors (Dalal, 2005). Although in many researches (Dalal, 2005) OCBs and CWBs have a negative relation, in the real world, we can see the fact that individuals are engaged in both behaviors at the same time. But the basic question is: how can someone accept a rule and break it simultaneously?

Spector and Fox (2002) express that positive and negative conditions at work influence an individual's emotional reactions, so that positive emotions are related to the OCBs and negative emotions related to the CWB. Similarly, in another paper Spector and Fox (2010) suggest that employees may engage in OCBs and CWBs as a way to deal with under-stimulation and injustice at work. To summarize, these result indicate that both OCBs and CWB may co-occur. In this paper and according to the findings of psychologists, moral licensing theory has been used to explain positive relations of OCBs and CWB.

\section{The Influence of Cultural background on Morally Licensed CWB}

As has been mentioned before, OCBs and the acquisition of moral licenses don't always lead to deviant and CWBs. Special conditions or context can be affected in forming deviant and counterproductive work behaviors. In this regard, organizational culture's dimensions have a critical role in the tendency of OCBs to CWB. This is because organizational culture often has a robust impact on an employee's behavior and attitudes between supervisors and employees. Organizational culture outlines the dos and don'ts of organizational life. Therefore investigation this relationship without taking into account the organizational culture's dimensions would be incomplete. 
Generally, the term of "organizational culture" induces a positive meaning in relation to the organization that is related to effectiveness and efficiency in the organization. The culture of an organization however is made up from many factors which have profound and positive impacts on organizational culture and help to create and reinforce to constructive culture. At the same time, it is important to keep in mind that these impacts can be dysfunctional and negative.

Previous researches on the definitions of organizational culture have concentrated on values. While values are important factors in organizational culture, they often are gained in the family. In fact, organizational culture is the way in which employees receive and interpret conditions and how they respond to these conditions. Therefore, organizational culture, especially those dimensions that related to the OCBs, can be defined by organizational work performance. Schein (1990) defined organizational culture as 1) a pattern of basic assumptions, 2) invented, discovered, or developed by a given group, 3) as it learns to cope with its problems of external adaptation and internal integration, 4) that has worked well enough to be considered valid and, therefore 5) is to be taught to new members as the 6) correct way to perceive, think, and feel in relation to those problems. In Figure 3, different dimensions of organizational culture are presented based on the views of various researchers in the field of culture and organizational culture (Van den Berg \& Wilderom, 2004).

Figure 3. Different dimensions of organizational culture in the views of various researchers

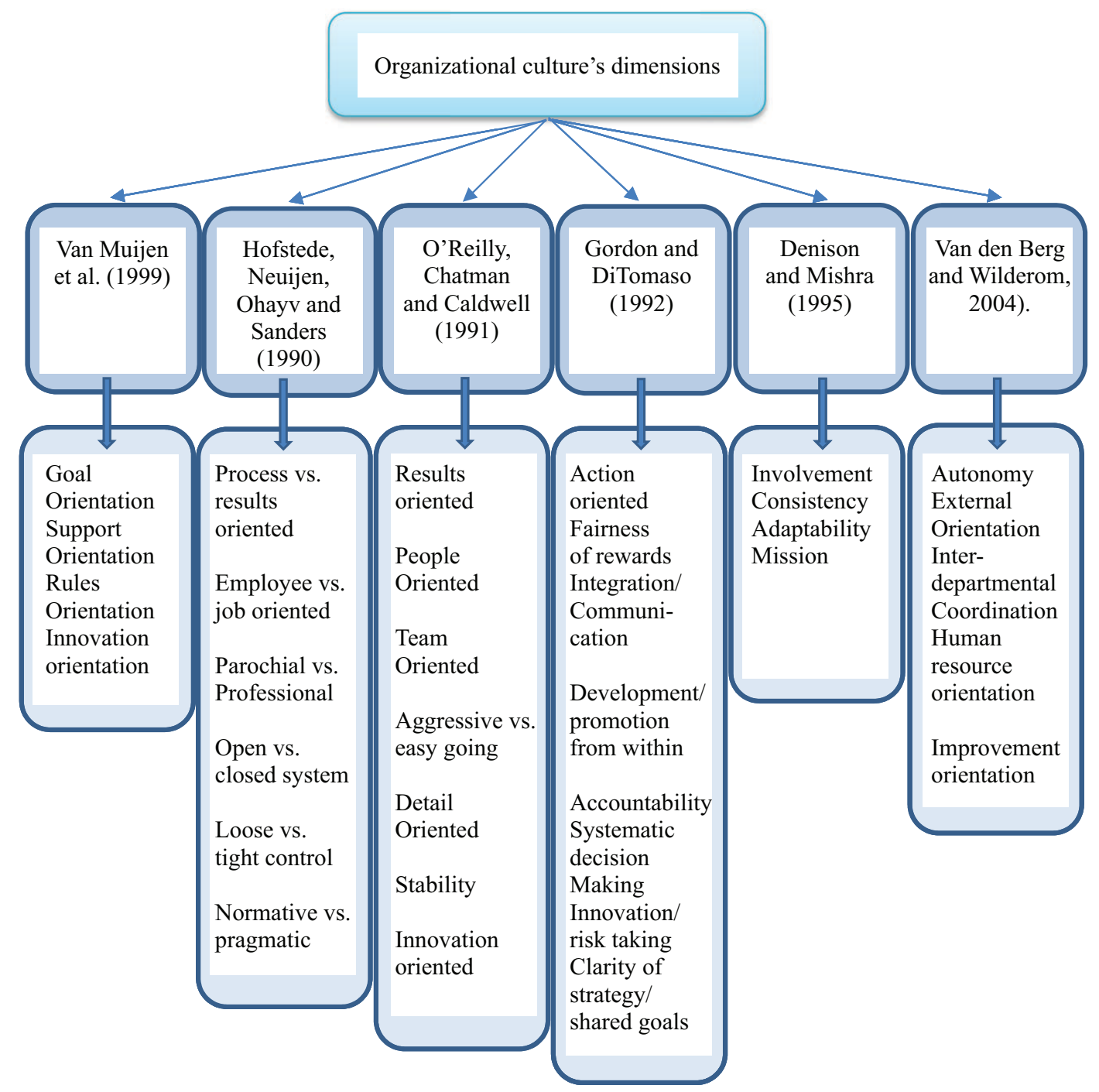


In fact, organizational culture is derived from the characteristics of national culture and administrative organization as well. There are several key organizational culture features that are related to OCBs. Findings show that organizational justice is used to foresee OCBs, so that organizational justice improves employees' trust and encourages them to exhibition OCBs (Jafari \& Bidarian, 2012). Another key organizational culture feature is hierarchy in an organization, which has been considered as power distance in Hofstede's works. In hierarchical organization people from high levels of hierarchy have power to influence. This is putative, however this kind of behavior should reflect fairness. Through time, these relationships may change from instrumental to agreement relationships based on communication satisfaction, trust and faith like covenantal relationships (Graham \& Organ, 1993). According to Earley and Calic (2018), reducing power distance in an organization leads to the tendency of legitimate relations becoming more personal agreement and conciliatory relations being crucial for displaying of OCBs.

In another study, Mohanty and Rath (2012) find that there is a significant correlation between all organizational culture variables (belief and norms, individual autonomy, individual responsibility, conflict tolerance, structure, risk tolerance, and support) and organizational citizenship behavior variables (altruism, conscientiousness, sportsmanship, courtesy and civic virtue). According their results, culture if nurtured can instruct citizenship behaviors in employees within the organization. It can be considered that strengthening the cultural roots of an organization can lead to form citizenship behavior across all sectors in an organization. Therefore strong organizational culture that is characterized by fairness with employees, caring and empathy, employee empowerment, career enriching opportunities, equitable payment and benefits, accurate job-person matching, honesty and ethics and safe working conditions reduce deviant and criminal behavior at the workplace and have a positive impact on formation of OCBs (Elias, 2013).

Despite of positive dimensions of organizational culture and their effects on forming extra role behaviors in an organization and the negative relation of OCBs and CWB, moral licensing theory and an abusive climate in an organization as well as dysfunctional culture dimensions can provide a potential explanation for why individuals are willing to conduct deviant behaviors.

When organizational culture induces to do more with less as an organizational imperative and supervisors expect employees to engage in extra role behaviors and OCBs, OCBs are not completely voluntary. In such situations the employees engage in OCBs because they are worried that their supervisors punish them, or that they lose their job. On the other hand, increasing OCBs reduces their values to the norms, in fact becoming part of organizational culture such that the personal costs (such as time and energy) may overshadow the benefits. When organizational culture induces turning the job into a contest of competitive scales, it leads to employees getting away from work and competition. It also causes friction among workers who want to be seen as the most committed employees. The continuation these conditions can be fragile for employees (Bolino \& et al, 2013; Balthazard, Cooke \& Potter, 2006). When organizational culture is not supportive and puts employees under pressure to engage in OCBs, forcing them to do these behaviors e.g. when their supervisors ruins an employee's vacation, or when the organizational culture is oppositional and supervisors just see the dark sides OCBs and looking for mistakes behavior of employees because they believe that OCBs detract from their in-role performance (Bolino \& et al., 2013; Balthazard, Cooke \& Potter, 2006). All of these can have negative outcomes and lead to deviant and counterproductive work behaviors.

\section{CONCLUSION}

In an organization, employees while engaging in productive behaviors - in-role behaviors and even extra-role behaviors, at the same time may engage in destructive behaviors that are contradicted with organizational goals, rules and norms. In this way, the role of organizational culture is very crucial. 
It is important to know how organizational context and cultural background affect employee's motivations and their tendency from OCBs to CWBs. When organizational culture is not supportive, or the atmosphere of the organization is too competitive, or if managers and supervisors consider OCBs as employee's main duties (Bolino \& et al., 2013; Balthazard, Cooke \& Potter, 2006); all of these things can lead to OCBs turn to CWBs. On the other hand, employees are interested to preserve a consistent level of moral identity and their credit in their organizations or in view of their colleagues, to prevent strict and negative judgment from others (Nisan, 1990). Therefore, they try to obtain ethical permission and moral licenses by relying on OCBs which have been done in the past. This subsequently lets themselves to engage in CWB without worrying about losing their credibility and reputation in the organization.

\section{Literature}

Appelbaum, S. H., Iaconi, G. D., \& Matousek, A. (2007). Positive and negative deviant workplace behaviors: causes, impacts, and solutions. Corporate Governance: The International Journal of Business in Society, 7(5), 586-598.

Balthazard, P. A., Cooke, R. A., \& Potter, R. E. (2006). Dysfunctional culture, dysfunctional organization: Capturing the behavioral norms that form organizational culture and drive performance. Journal of Managerial Psychology, 21(8), 709-732.

Bell, S. J., \& Menguc, B. (2002). The employee-organization relationship, organizational citizenship behaviors, and superior service quality. Journal of Retailing, 78(2), 131-146.

Bergeron, D. M. (2007). The potential paradox of organizational citizenship behavior: Good citizens at what cost?. Academy of Management Review, 32(4), 1078-1095.

Bergeron, D., Ostroff, C., Schroeder, T., \& Block, C. (2014). The dual effects of organizational citizenship behavior: Relationships to research productivity and career outcomes in academe. Human Performance, 27(2), 99-128.

Bettencourt, L. A., \& Brown, S. W. (1997). Contact employees: Relationships among workplace fairness, job satisfaction and prosocial service behaviors. Journal of Retailing, 73(1), 39-61.

Bhal, K. T. (2006). LMX-citizenship behavior relationship: Justice as a mediator. Leadership \& Organization Development Journal, 27(2), 106-117.

Blanken, I., van de Ven, N., Zeelenberg, M., \& Meijers, M. H. (2014). Three attempts to replicate the moral licensing effect. Social Psychology, 45(3), 232.

Blanken, I., van de Ven, N., \& Zeelenberg, M. (2015). A meta-analytic review of moral licensing. Personality and Social Psychology Bulletin, 41(4), 540-558.

Bolino, M. C. (1999). Citizenship and impression management: Good soldiers or good actors?. Academy of Management Review, 24(1), 82-98.

Bolino, M. C., \& Turnley, W. H. (2005). The personal costs of citizenship behavior: the relationship between individual initiative and role overload, job stress, and work-family conflict. Journal of Applied Psychology, 90(4), 740.

Bolino, M. C., Klotz, A. C., Turnley, W. H., \& Harvey, J. (2013). Exploring the dark side of organizational citizenship behavior. Journal of Organizational Behavior, 34(4), 542-559.

Bolino, M. C., \& Klotz, A. C. (2015). The paradox of the unethical organizational citizen: The link between organizational citizenship behavior and unethical behavior at work. Current Opinion in Psychology, 6, 45-49.

Borman, W. C., \& Penner, L. A. (2001). Citizenship performance: Its nature, antecedents, and motives. In B. W. Roberts \& R. Hogan (Eds.), Decade of behavior. Personality psychology in the workplace (pp. 45-61). Washington, DC, US: American Psychological Association.

Campbell Pickford, H., \& Joy, G. (2016). Organisational Citizenship Behaviours: Definitions and Dimensions. Available at: http://eureka.sbs.ox.ac.uk/6265/1/2016-31.pdf

Chughtai, A. A., \& Zafar, S. (2006). Antecedents and consequences of organizational commitment among Pakistani university teachers. Applied HRM Research, 11, 39-64.

Dalal, R. S. (2005). A meta-analysis of the relationship between organizational citizenship behavior and counterproductive work behavior. Journal of Applied Psychology, 90(6), 1241.

Dash, S., \& Pradhan, R. K. (2014). Determinants and consequences of organizational citizenship behavior: A theoretical framework for Indian manufacturing organisations. International Journal of Business and Management Invention, 3(1), 17-27. 
Dimitriades, Z. S. (2007). The influence of service climate and job involvement on customer-oriented organizational citizenship behavior in Greek service organizations: a survey. Employee Relations, 29(5), 469-491.

Earley, P., \& Calic, G. (2018-08-25). A Cultural Perspective on Organizational Citizenship Behavior. In (Ed.), The Oxford Handbook of Organizational Citizenship Behavior: Oxford University Press,. Retrieved 18 Jan. 2019, from http:/www.oxfordhandbooks.com/view/10.1093/oxfordhb/9780190219000.001.0001/oxfordhb$-9780190219000-\mathrm{e}-29$.

Elias, S. M. (Ed.). (2013). Deviant and criminal behavior in the workplace. NYU Press.

Farh, J. L., Earley, P. C., \& Lin, S. C. (1997). Impetus for action: A cultural analysis of justice and organizational citizenship behavior in Chinese society. Administrative Science Quarterly, 42(3), 421-444, DOI: 10.2307/2393733

Flynn, F. J. (2003). How much should I give and how often? The effects of generosity and frequency of favor exchange on social status and productivity. Academy of Management Journal, 46(5), 539-553.

Graham, J. W., \& Organ, D. W. (1993). Commitment and the covenantal organization. Journal of Managerial Issues, 5(4), 483-502.

Grant, A. M. (2007). Relational job design and the motivation to make a prosocial difference. Academy of Management Review, 32(2), 393-417.

Grant, A. M., \& Schwartz, B. (2011). Too much of a good thing: The challenge and opportunity of the inverted U. Perspectives on Psychological Science, 6(1), 61-76.

Halbesleben, J., \& Bellairs, T. (2018-08-25). What Are the Motives for Employees to Exhibit Citizenship Behavior?: A Review of Prosocial and Instrumental Predictors of Organizational Citizenship Behavior. In (Ed.), The Oxford Handbook of Organizational Citizenship Behavior. : Oxford University Press,. Retrieved 18 Jan. 2019, from http:/www.oxfordhandbooks.com/view/10.1093/oxfordhb/9780190219000.001.0001/oxfordhb$-9780190219000-\mathrm{e}-16$.

Hanson, M. A., \& Borman, W. C. (2006). Citizenship performance: An integrative review and motivational analysis. Performance measurement: Current Perspectives and Future Challenges, 141-173.

Jafari, P., \& Bidarian, S. (2012). The relationship between organizational justice and organizational citizenship behavior. Procedia-Social and Behavioral Sciences, 47, 1815-1820.

Jex, S. M., \& Britt, T. W. (2008). Organizational Psychology: A Scientist-Practitioner Approach (2. Ausg.). Hoboken, New Jersey, Vereinigte Staaten: John Wiley \& Sons.

Khalid, S. A., \& Ali, H. (2005). The effects of organizational citizenship behavior on withdrawal behavior. International Journal of Management and Entrepreneurship, 1(1), 30-40.

Kim, Y. J., Van Dyne, L., Kamdar, D., \& Johnson, R. E. (2013). Why and when do motives matter? An integrative model of motives, role cognitions, and social support as predictors of OCB. Organizational Behavior and Human Decision Processes, 121(2), 231-245.

Klotz, A. C., \& Bolino, M. C. (2013). Citizenship and counterproductive work behavior: A moral licensing view. Academy of Management Review, 38(2), 292-306.

Lo, M. C., Ramayah, T., \& Kueh Swee Hui, J. (2006). An Investigation of Leader Member Exchange Effects on Organizational Citizenship Behavior in Malaysia. Journal of Business \& Management, 12(1), 5-23.

Miller, D. T., \& Effron, D. A. (2010). Psychological license: When it is needed and how it functions. In Advances in experimental social psychology, (Vol. 43, pp. 115-155). Academic Press.

Mohanty, J., \& Rath, B. (2012). Influence of organizational culture on organizational citizenship behavior: A three-sector, Global Journal of Business Research, 6(1), 65-76,.

Morrison, E. W. (1994). Role definitions and organizational citizenship behavior: The importance of the employee>s perspective. Academy of Management Journal, 37(6), 1543-1567.

Muafi, J. (2011). Causes and consequence deviant workplace behavior. International Journal of Innovation, Management and Technology, 2(2), 123-126.

Nisan, M., \& Horenczyk, G. (1990). Moral balance: The effect of prior behaviour on decision in moral conflict. British Journal of Social Psychology, 29(1), 29-42.

Organ, D. W. (1997). Organizational citizenship behavior: It〉s construct clean-up time. Human Performance, $10(2), 85-97$.

Organ, D. W. (1988). Issues in organization and management series. Organizational citizenship behavior: The good soldier syndrome. Lexington, MA, England: Lexington Books/DC Heath and Com.

Organ, D. W., Podsakoff, P. M., \& MacKenzie, S. B. (2005). Organizational citizenship behavior: Its nature, antecedents, and consequences. Thousand Oaks, CA: SAGE Publications.

Paillé, P. (2009). Assessing organizational citizenship behavior in the French context: Evidence for the four-dimensional model. The Journal of Psychology, 143(2), 133-146. 
Penner, L. A., \& Orom, H. (2010). Enduring goodness: A person-by-situation perspective on prosocial behavior. In M. Mikulincer, \& P. R. Shaver (Eds.), Prosocial motives, emotions, and behavior: The better angels of our nature (pp. 55-72). Washington, DC: American Psychological Association.

Pierce, J. R., \& Aguinis, H. (2013). The too-much-of-a-good-thing effect in management. Journal of Management, 39(2), 313-338.

Posdakoff, P. M., \& Mackenzie, S. B. (1994). Organizational citizenship behaviors and sales unit effectiveness. Journal of Marketing Research, 351-363.

Podsakoff, P. M., MacKenzie, S. B., \& Bommer, W. H. (1996). Meta-analysis of the relationships between Kerr and Jermierss substitutes for leadership and employee job attitudes, role perceptions, and performance. Journal of Applied Psychology, 81(4), 380.

Podsakoff, P. M., Ahearne, M., \& MacKenzie, S. B. (1997). Organizational citizenship behavior and the quantity and quality of work group performance. Journal of Applied Psychology, 82(2), 262.

Podsakoff, P. M., \& MacKenzie, S. B. (1997). Impact of organizational citizenship behavior on organizational performance: A review and suggestion for future research. Human Performance, 10(2), 133-151.

Podsakoff, P. M., MacKenzie, S. B., Paine, J. B., \& Bachrach, D. G. (2000). Organizational citizenship behaviors: A critical review of the theoretical and empirical literature and suggestions for future research. Journal of Management, 26(3), 513-563.

Rioux, S. M., \& Penner, L. A. (2001). The causes of organizational citizenship behavior: a motivational analysis. Journal of Applied Psychology, 86(6), 1306.

Robinson, S. L., \& Bennett, R. J. (1995). A typology of deviant workplace behaviors: A multidimensional scaling study. Academy of Management Journal, 38(2), 555-572.

Rosenfeld, P., Giacalone, R. A., \& Riordan, C. A. (1995). Impression management in organizations: Theory, measurement, practice. Van Nostrand Reinhold.

Salamon, S. D., \& Deutsch, Y. (2006). OCB as a handicap: An evolutionary psychological perspective. Journal of Organizational Behavior: The International Journal of Industrial, Occupational and Organizational Psychology and Behavior, 27(2), 185-199.

Schein, E. H. (1990). Organizational Culture, American Psychologist, 45(2), 109-119.

Simbrunner, P., \& Schlegelmilch, B. B. (2017). Moral licensing: a culture-moderated meta-analysis. Management Review Quarterly, 67(4), 201-225.

Skyvington, S. (2014). License to Misbehave: Organizational Citizenship Behavior as a Moral License for Deviant Reactions to Abusive Supervision (Master's thesis, University of Waterloo).

Spector, P. E., \& Fox, S. (2010). Theorizing about the deviant citizen: An attributional explanation of the interplay of organizational citizenship and counterproductive work behavior. Human Resource Management Review, 20(2), 132-143.

Spector, P. E., \& Fox, S. (2002). An emotion-centered model of voluntary work behavior: Some parallels between counterproductive work behavior and organizational citizenship behavior. Human Resource Management Review, 12(2), 269-292.

Spreitzer, G., \& Sonenshein, S. (2003). Positive Deviance and Extraordinary Organizing. In K. S. Cameron, J. E. Dutton, \& R. E. Quinn (Eds.), Positive organizational scholarship: Foundations of a New Discipline (pp. 207-224), San Francisco, USA: Berrett-Koehler Publishers, Inc.

Tranfield, D., Denyer, D., \& Smart, P. (2003). Towards a methodology for developing evidence-informed management knowledge by means of systematic review. British journal of management, 14(3), 207-222.

Van den Berg, P. T., \& Wilderom, C. P. (2004). Defining, measuring, and comparing organisational cultures. Applied Psychology, 53(4), 570-582.

Walz, S. M., \& Niehoff, B. P. (1996, August). Organizational citizenship behaviors and their effect on organizational effectiveness in limited-menu restaurants. In Academy of management proceedings, 1996(1), 307-311). Briarcliff Manor, NY 10510: Academy of Management.

Yam, K. C., Klotz, A. C., He, W., \& Reynolds, S. J. (2017). From good soldiers to psychologically entitled: Examining when and why citizenship behavior leads to deviance. Academy of Management Journal, 60(1), 373-396. 